\title{
TEMPAT HIBURAN EKSPRES UNTUK DOMESTIK
}

\author{
Blandina Sherin ${ }^{1)}$, Budi Adelar Sukada ${ }^{2)}$ \\ 1) Program Studi S1 Arsitektur, Fakultas Teknik, Universitas Tarumanagara, sherinblandina@gmail.com \\ 2) Program Studi S1 Arsitektur, Fakultas Teknik, Universitas Tarumanagara, budisukada@yahoo.com \\ Masuk: 09-01-2020, revisi: 28-01-2020, diterima untuk diterbitkan: 09-05-2020 (doi: 10.24912/stupa.v2i1.6778)
}

\begin{abstract}
Abstrak
Indonesia memiliki luas wilayah dengan dominasi $75 \%$ lautan dan 25\% darat menyebabkan Maritim menjadi poros terkuat negara Indonesia. Namun kekurangpedulian masyarakat Indonesia akan kekayaan alam bawah laut menjadi masalah utama Wisata Laut dibeberapa titik Indonesia kurang berkembang. Oleh karena itu bagaimana Arsitektur dapat mewadahi kegiatan dan kemajuan Pariwisata Indonesis khususnya dibidang Maritim. Pada kasus ini, terdapat di Muara Angke, dimana terdapat Wisata menuju Pulau Seribu melalui Pelabuhan Kaliadem, namun fasilitas di Pelabuhan yang tidak memadai sehingga pengunjung merasa tidak nyaman untuk menggunakan Pelabuhan dan minat untuk mengunjungi Wisata Maritim kurang. Maka dari itu untuk menyelesaikan kasus ini, diperlukan sarana yang dapat menambah minat dan juga kenyamanan Pengunjung Pelabuhan Kaliadem, pendekatan desain melalui kriteria Tempat Ketiga oleh Ray Oldenburg, salah satunya adalah 'Perasaan yang Menyenangkan', hasil akhir dari desain adalah wadah bagi Pengunjung Pelabuhan untuk bersenang-senang dan dapat berinteraksi satu sama lain sembari menunggu jadwal keberangkatan dan juga sebagai tempat beristirahat sejenak setelah berpulang kembali.
\end{abstract}

Kata kunci: maritim; menyenangkan; wisata

\begin{abstract}
Indonesia has an area of $75 \%$ by sea and $25 \%$ by land, making Maritime the strongest axis of the Indonesian state. However, the Indonesian are not corcern enough to the natural habitat of the underwater, it becomes the main problem of Sea Tourism in some areas of Indonesia are less developed. Therefore, how can architecture accommodate the activities of Indonesian tourism, especially in the maritime field. In this case, there is Muara Angke, where there is a tour to Seribu Island via Kaliadem Port, but the facilities at the Port are inadequate so that visitors feel uncomfortable using the Port and lack of interest in visiting Maritime Tourism. Therefore, to resolve this case, facilities are needed to increase interest and also increased visitors to the Kaliadem Port, the design began by the criteria of Third Place by written by Ray Oldenburg, one of which is 'The Mood is Playful', the final result of the design provided for visitors of the Port to Have Fun and have a nice social interaction while waiting for the schedule to aboard and also as a place to rest a while after returning from the trip.
\end{abstract}

\section{Keyword: maritime; playful; tourism}

\section{PENDAHULUAN}

Istilah Third Place diciptakan pertama kali pada tahun 1991 oleh Sosiolog Urban Ray Oldenburg, ia menjelaskan dalam bukunya tentang delapan kriteria 'The Great Good Place' yang menciptakan Third Place. Salah satu kriteria Third Place menurut Ray Oldenburg adalah Conversation is the main activity: Playful and happy conversation is the main focus of activity in third places, although it is not required to be the only activity. The tone of conversation is usually light-hearted and humorous; wit and good-natured playfulness are highly valued. Dari kriteria ini dapat diartikan bahwa Percakapan adalah kegiatan utama yang mengacu pada kriteria Third Place : The Mood is Playful, Nada percakapan di tempat ketiga tidak pernah ditandai dengan 
ketegangan atau permusuhan. Sebaliknya, tempat ketiga memiliki sifat yang menyenangkan, di mana percakapan yang terjadi secara bebas dan tidak menyinggung perasaan lawan bicara.

Jakarta memiliki daya tarik Wisata Maritim terbesar di Kepulauan Seribu, akses menuju Kepulauan Seribu dapat melalui Dermaga Ancol dan Pelabuhan Kaliadem yang berada di Muara Angke, dalam kasus ini Pelabuhan Kaliadem berada dikawasan Nelayan dengan fasilitas dan aksesibilitas yang kurang memadai bagi pengunjung Pelabuhan. Kondisi ini tidak sesuai dengan salah satu karakteristik Third Place yaitu The Mood is Playful. Untuk menyelesaikan masalah yang terjadi dibutuhkan pendekatan secara Conversation is The Main Activity.

Pendekatan ini dapat dilakukan dengan memberikan sebuah sarana bagi Pengguna Pelabuhan saat menunggu jadwal keberangkatan atau saat berpulang menuju Pelabuhan yang dapat meningkatan interaksi antar pengunjung dan juga membangun suasana Pelabuhan yang menyenangkan dengan sarana-sarana yang bersifat Playful dan Relaxing. Dari latar belakang tersebut, terdapat beberapa masalah yang ditemukan dan dapat menjadi bahan penelitian, antara lain :

- Arsitektur menjadi wadah bagi fasilitas umum Pelabuhan khususnya untuk pengguna Pelabuhan;

- Teori Third Place : The Mood is Playful dan penerapan kedalam fasilitas Pelabuhan;

- $\quad$ Lokasi tapak dan Pelabuhan Kaliadem yang sulit untuk diakses;

- Merubah pandangan Pelabuhan dari tempat 'menunggu' menjadi tempat 'hiburan ekspres'

Sarana ini dapat menjadi daya tarik di Kawasan Muara Angke, terutama di Pelabuhan Kaliadem, yang pada saat ini belum memenuhi kriteria Third Place yaitu The Mood is Playful, program yang akan digunakan adalah Komersil dan Hiburan yang mendukung Kawasan Muara Angke.

\section{KAJIAN LITERATUR}

Third Place memiliki sejumlah pembangunan yang penting bagi masyarakat. Bergantung pada lokasi kawasan, kelas dan latar belakang sosial yang "diratakan" namun ironisnya jarang terjadi pada masa kini, dengan orang-orang membutuhkan perlakuan sosial secara merata. Percakapan tidak formal adalah kegiatan utama dan fungsi penyambung terpenting.

Oldenburg (1997) menyebut "tempat pertama" seseorang sebagai rumah dan tempat tinggal seseorang. "Tempat kedua" adalah tempat kerja - di mana orang mungkin menghabiskan sebagian besar waktu mereka. Maka, tempat ketiga adalah "jangkar" kehidupan komunitas dan memfasilitasi dan mendorong interaksi yang lebih luas dan lebih kreatif. Dengan kata lain, "tempat ketiga Anda adalah di mana Anda bersantai di depan umum, di mana Anda berjumpa dengan wajah-wajah yang sudah dikenal dan membuat kenalan baru."

Pandangan Oldenburg tentang tempat ketiga dengan delapan karakteristik:

- Neutral Ground

Penghuni tempat ketiga memiliki sedikit atau tidak ada kewajiban untuk berada di sana. Mereka tidak terikat ke daerah itu secara finansial, politik, hukum, atau sebaliknya dan bebas untuk datang dan pergi sesuka mereka.

- Leveler (A Leveling Place)

Tempat ketiga tidak mementingkan status individu dalam suatu masyarakat. Status ekonomi atau sosial seseorang tidak penting di tempat ketiga, memungkinkan rasa kesamaan di antara penghuninya. Tidak ada prasyarat atau persyaratan yang akan mencegah penerimaan atau partisipasi di tempat ketiga.

- Conversation is The Main Activity Obrolan menyenangkan dan bahagia adalah fokus utama dari aktivitas di tempat ketiga, meskipun tidak harus menjadi satu-satunya aktivitas. Nada percakapan biasanya ringan dan lucu; kecerdasan dan sifat main-main yang baik sangat dihargai.

- Accesibility and Accomodation 
Tempat ketiga harus terbuka dan mudah diakses oleh mereka yang menempatinya. Mereka juga harus akomodatif, artinya mereka memenuhi kebutuhan penghuninya, dan semua penghuni merasa kebutuhan mereka telah terpenuhi.

- $\quad$ The Regulars

Tempat ketiga menampung sejumlah pengunjung tetap yang membantu memberi ruang nada, dan membantu mengatur suasana hati dan karakteristik daerah. Reguler ke tempat ketiga juga menarik pendatang baru, dan ada di sana untuk membantu seseorang yang baru ke ruang merasa diterima dan ditampung.

- A Low Profile

Tempat ketiga secara karakteristik sehat. Bagian dalam tempat ketiga adalah tanpa pemborosan atau kebesaran, dan memiliki perasaan yang sederhana. Tempat ketiga tidak pernah sombong atau sok, dan menerima semua jenis individu, dari berbagai lapisan masyarakat.

- The Mood is Playful

Nada percakapan di tempat ketiga tidak pernah ditandai dengan ketegangan atau permusuhan. Sebaliknya, tempat ketiga memiliki sifat yang menyenangkan, di mana percakapan cerdas dan olok-olok sembrono tidak hanya umum, tetapi sangat dihargai.

- A Home Away from Home

Penghuni tempat ketiga akan sering memiliki perasaan hangat, kepemilikan, dan kepemilikan yang sama seperti di rumah mereka sendiri. Mereka merasa sepotong diri mereka berakar di ruang, dan mendapatkan regenerasi spiritual dengan menghabiskan waktu di sana.

Ketika "tempat ketiga" menjadi lebih populer, beberapa ruang kantor rekan kerja telah menganut konsep ini sebagai dasar dari desain interior mereka. Varian bentuk konsep termasuk "rumah kopi komunitas" dan "ruang tamu komunitas", sebuah istilah yang telah diadopsi oleh beberapa organisasi untuk menggambarkan model "ruang ketiga" yang dikelola secara kooperatif yang mencakup fungsi komersial atau non-komersial dengan penekanan pada penyediaan ruang bebas untuk interaksi sosial.

\section{Pelabuhan}

Pelabuhan adalah sebuah fasilitas yang berada di ujung Samudera, Sungai, atau Danau untuk menerima kapal dan memindahkan barang kargo maupun penumpang ke dalamnya. Pelabuhan biasanya memiliki alat-alat yang dirancang khusus untuk memuat dan membongkar muatan kapal-kapal yang berlabuh. Crane dan gudang berpendingin juga disediakan oleh pihak pengelola maupun pihak swasta yang berkepentingan. Sering pula disekitarnya dibangun fasilitas penunjang seperti pengalengan dan pemrosesan barang. Peraturan Pemerintah RI No.69 Tahun 2001 mengatur tentang pelabuhan dan fungsi serta penyelengaraannya.

Pelabuhan juga dapat di definisikan sebagai daerah perairan yang terlindung dari gelombang laut dan di lengkapi dengan fasilitas terminal meliputi :

- Dermaga, tempat di mana kapal dapat bertambat untuk bongkar muat barang.

- Crane, untuk melaksanakan kegiatan bongkar muat barang.

- Gudang Laut (transito), tempat untuk menyimpan muatan dari kapal atau yang akan di pindah ke kapal.

Pelabuhan juga merupakan pintu gerbang untuk masuk ke suatu daerah tertentu dan sebagai prasarana penghubung antar daerah, antar pulau, bahkan antar negara. (Triatmodjo, 2009)

\section{Rest area}

Dilihat dari kosakatanya "rest area " mempunyai dua suku kata yaitu "rest " dan " area ", yang mempunyai pengertian tempat beristirahat atau daerah istirahat. Sedangkan dalam tugas akhir ini rest area mempunyai batasan sebagai tempat yang mampu mewadahi berbagai kegiatan komersil. 
Berkaitan dengan fungsi rest area itu sendiri sebagai tempat beristirahat maka ada beberapa fasilitas jasa yang ditawarkan dalam rest area ini. Fasilitas itu adalah :

- Restoran \& Food Court Sebagai tempat beristirahat, maka keberadaan tempat makan ini menjadi kegiatan utama dalam rest area. Restoran berada di lantai 2 dengan sistem pelayanan dititikberatkan pada melayani diri sendiri, hal ini terlihat bahwa adanya meja prasmanan yang disediakan untuk para pengunjung. Sedangkan food court terletak di lantai 3, sistem pelayanan disini lebih kepada menyediakan makanan-makanan cepat saji yang tidak memerlukan waktu banyak untuk penyajiannya.

- Souvenir Shop Sebagai sarana untuk menjual barang-barang khas daerah Indramayu. Souvenir shop ini juga sebagai ajang penjualan barang-barang kerajinan penduduk setempat. Dengan adanya souvenir shop ini maka diharapkan kerajinan khas Indramayu dapat dikenal oleh khalayak ramai.

- Minimarket Menjual barang-barang yang dibutuhkan pengunjung dan lebih diutamakan pada penjualan minuman / makanan kecil yang diperlukan dalam melakukan perjalanan jauh. Gamezone Ajang bermain untuk melepas ketegangan setelah melakukan perjalanan jauh.

- ATM dan Wartel Sebagai sarana penunjang yang diperlukan untuk melancarkan aktifitas. Selain fasilitas yang telah diuraikan diatas, ada pula fasilitas yang memang disediakan untuk memenuhi kebutuhan kenyamanan para pengunjung.

\section{METODE PERANCANGAN}

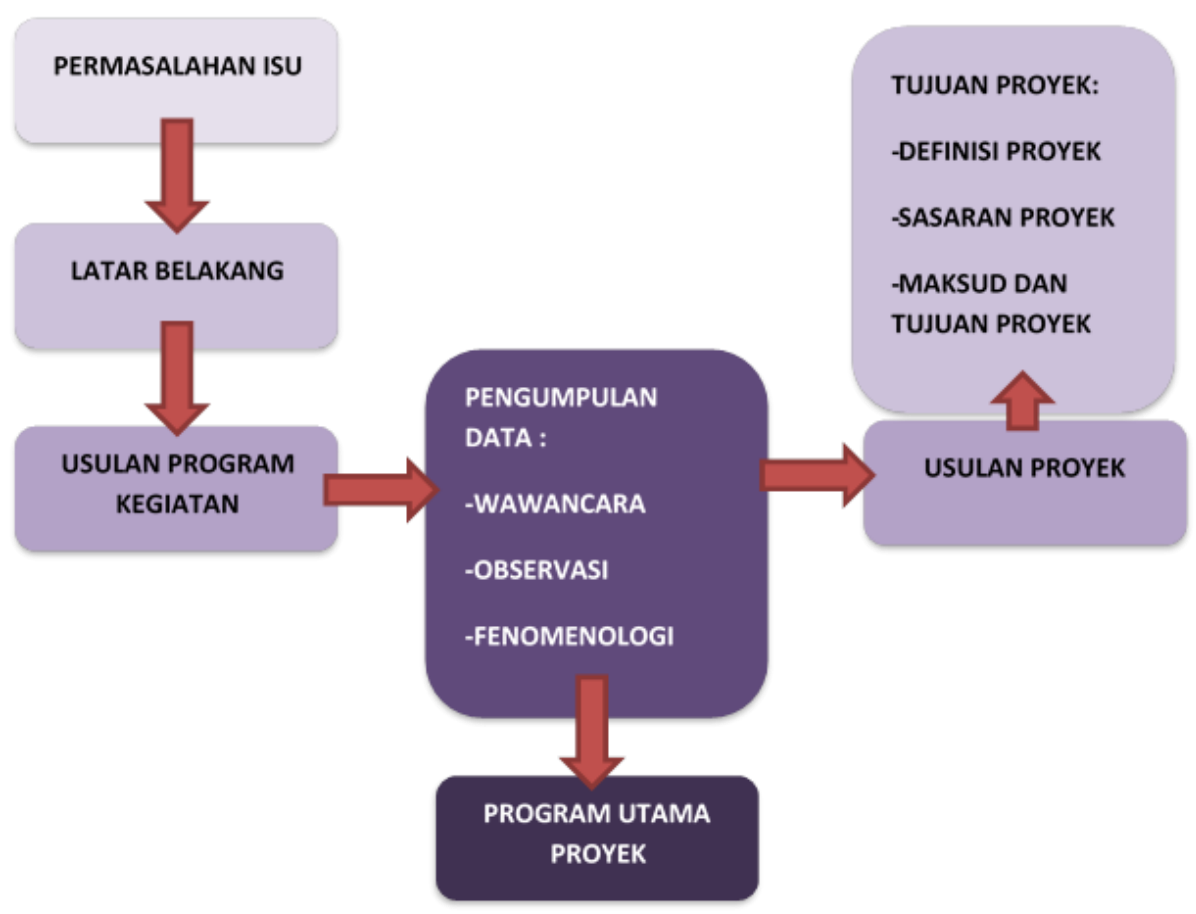

- Wawancara - Teknik pengumpulan data yang dilakukan melalui tatap muka dan tanya jawab langsung antara peneliti dan narasumber. Wawancara terbagi atas dua kategori, yakni wawancara terstruktur dan tidak terstruktur. Dalam penulisan Proposal ini penulis menggunakan metode wawancara tidak terstruktur. Wawancara tidak terstruktur adalah wawancara bebas. Peneliti tidak menggunakan pedoman wawancara yang berisi pertanyaan-pertanyaan spesifik, namun hanya memuat poin-poin penting dari masalah yang ingin digali dari responden. 
- Observasi - Dalam penulisan ini penulis menggunakan metode Participant Observation yaitu peneliti terlibat secara langsung dalam kegiatan sehari-hari orang atau situasi yang diamati sebagai sumber data. Dengan mengobservasi kegiatan dan aktivitas penumpang di tempat tunggu Pelabuhan Kaliadem saat menunggu kedatangan kapal dan juga penumpang yang baru kembali ke Pelabuhan.

- Fenomenologi - merupakan metode yang digunakan penulis untuk menyelidiki sebuah fenomena dari perspektif individu atau beberapa individu yang mengalaminya. Metode ini dipakai oleh penulis untuk melihat karakteristik dan pola aktivitas pengunjung Pelabuhan Muara Angke untuk mendapatkan program utama dalam proyek ini.

\section{DISKUSI DAN HASIL PENELITIAN}

Lokasi

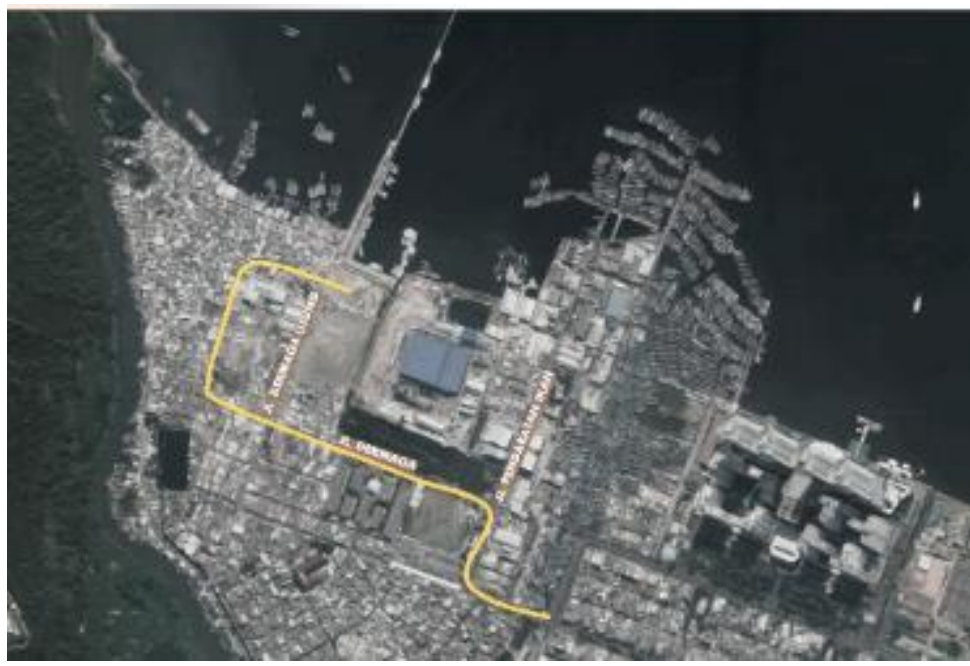

Gambar 1. Kawasan Muara Angke Sumber : Dokumen Pribadi (edit google maps)

Berada di samping Pelabuhan Kaliadem, Muara Angke. Akses memasuki tapak dapat melalui dua jalan, yaitu melewati Pelabuhan Kaliadem dan melewati Pasar Ikan Muara Angke. Jika melewati Pelabuhan, setelah itu harus berjalan kaki melewati plat pelabuhan menuju tapak (jalur pedestrian), jika melalui Pasar Ikan harus menggunakan kendaraan.

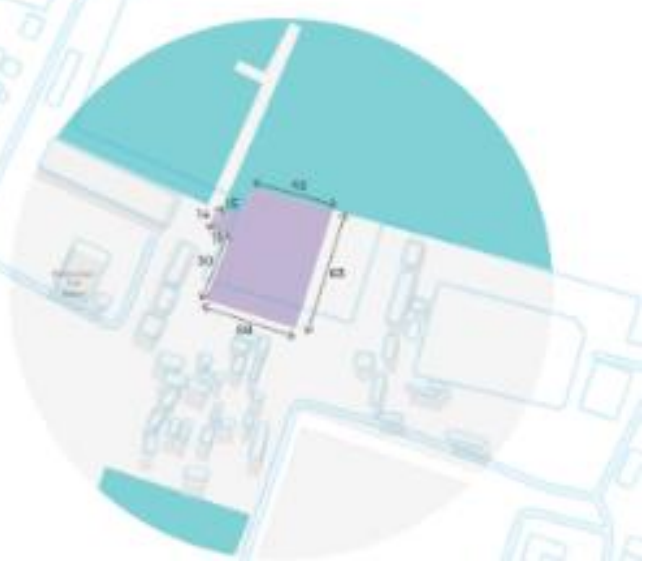

Gambar 2. Tapak Terpilih

Sumber : Penulis, 2019 


\section{Hasil Observasi}

Dari hasil observasi Pelabuhan Kaliadem, Pelabuhan sedang dalam renovasi ulang jadi tidak terdapat bangunan yang layak untuk pengunjung, hanya terdapat tempat menunggu terbuka yang berada ditempat parkir, dengan masalah utama adalah debu dari pasir dan juga bau. Dan dari hasil Observasi pengunjung Pelabuhan, penulis mengkategorikan aktivitas kedalam program yang memungkinkan bagi pengguna Pelabuhan Kaliadem. Program-program utama tersebut dimasukkan dalam kategori Entertainment dan Commercial. Program muncul dari empat keyword utama, yaitu : Fun, Entertain, Relax, Quick

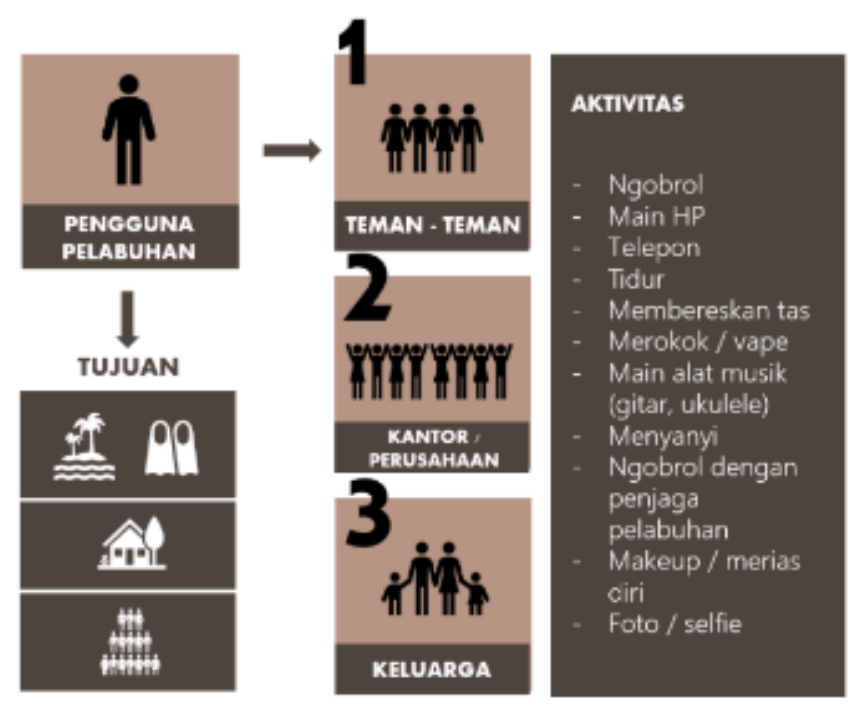

Gambar 3. Hasil Observasi Aktivitas Menunggu Pengguna Pelabuhan

Sumber : Penulis, 2019

Diatas adalah aktivitas penumpang Pelabuhan saat menunggu kapal yang akan tiba, dan dapat dua kata kunci, bored dan sleepy sehingga program harus bersifat Fun dan Entertain. Sedangkan saat penumpang kembali ke Pelabuhan didapat tiga kata kunci, Tired, Seasick dan Body Pain sehingga program dirancang untuk Relax dan Quick.

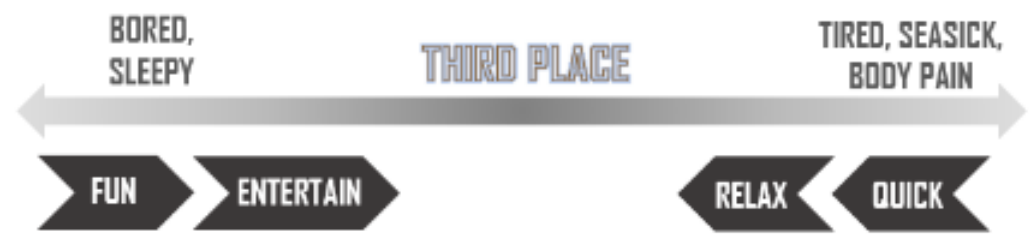

Gambar 4. Parameter Program Utama FREEDOM Sumber : Penulis, 2019

Didapatkan program-program utama, yaitu :

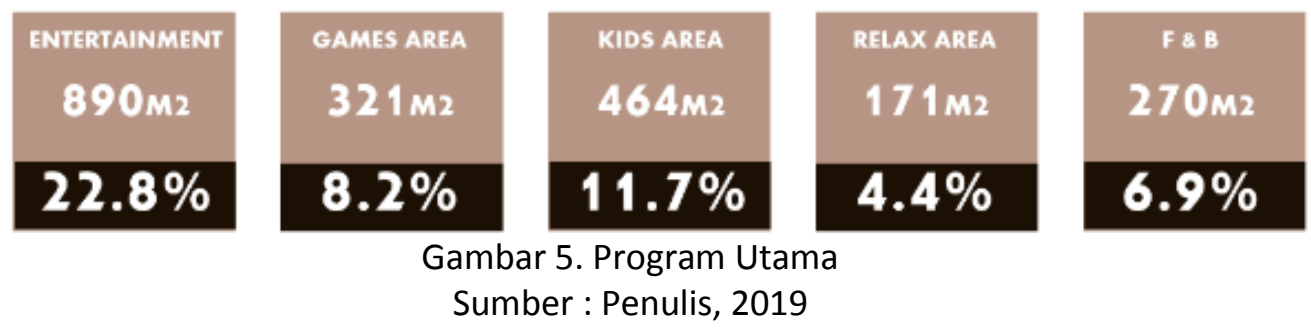




\section{Tema Konsep}

Konsep tema FREEDOM (Fun \& Relax Express Entertainment For Domestic) berasal dari hasil Observasi yang kemudian diterjemahkan menjadi beberapa kata kunci yang menghasilkan kata FREEDOM.
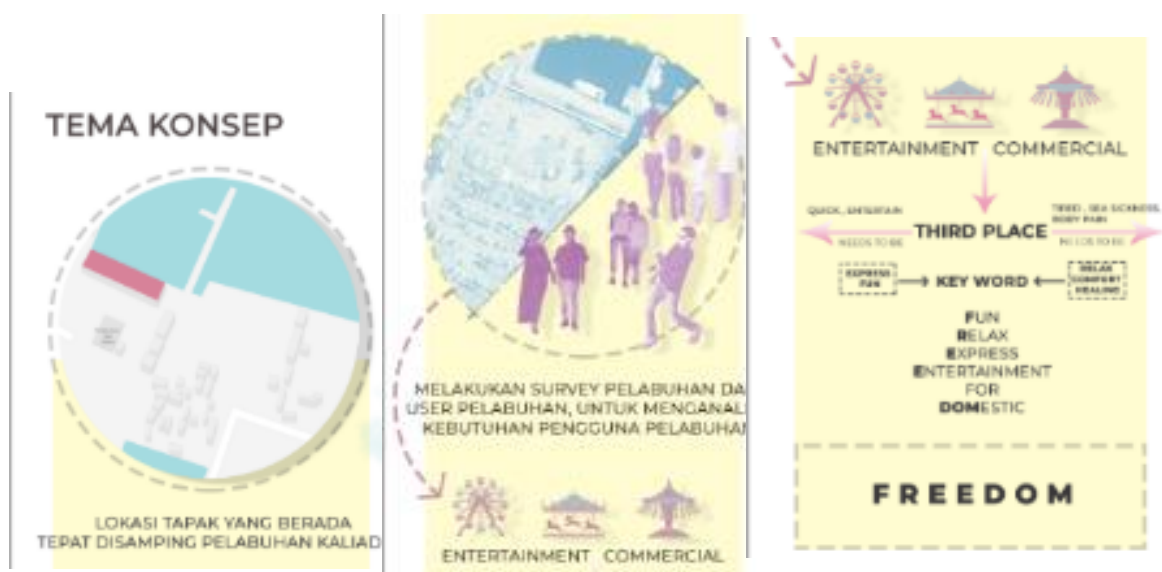

Gambar 6. Tema Konsep

Sumber : Penulis, 2019

\section{Gubahan Massa}
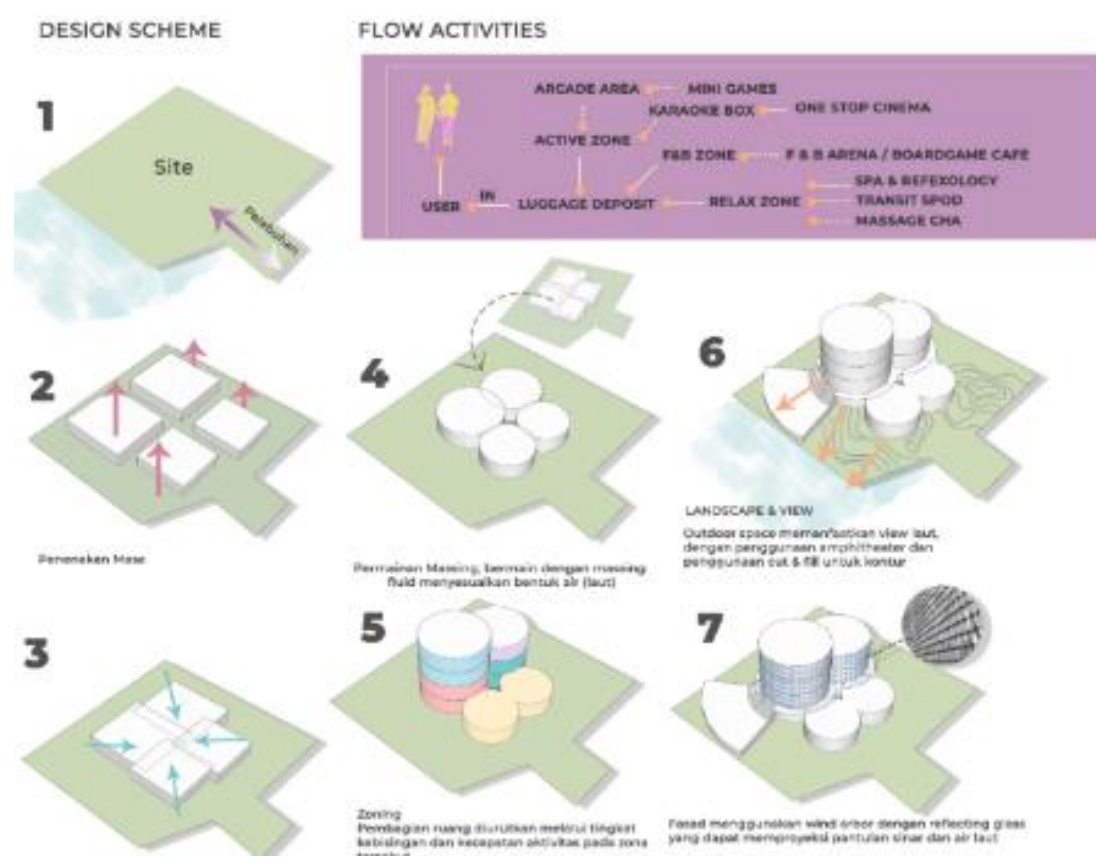

Gambar 7. Design Scheme dan Activity Flow

Sumber : Penulis, 2019

Proses Gubahan Massa bermula dari 2. pembagian zoning kebutuhan pengguna pelabuhan, kemudian massing disusun vertical agar mass tidak bulky 3. Massing di overlap menciptakan ruang-ruang yang saling berhubungan 4 . Pembentukan circular massing (mencirikan flow air) karena tapak berada ditepi laut 5. Zoning ruang, ditentukan berdasarkan kecepatan aktivitas pada zone tersebut, semakin lama berlangsungnya, ruang akan diletakkan paling atas dan juga kebutuhan privasi dan ketenangan pada zone juga menentukan peletakannya. 6 . Landscape \& view didesain mengahadap ke laut 7. Fasad, menggunakan wind arbor yang akan bergerak menciptakan gelombang saat tertiup angin, dan material reflecting glass yang akan merefleksikan laut. 


\section{Deskripsi Desain}

FREEDOM, tempat yang merupakan fasilitas Third Place bagi pengguna Pelabuhan Kaliadem, berada disamping Pelabuhan dengan akses langsung melalui pelat Pelabuhan. Freedom menjadi tempat bersantai dan bermain sejenak sebelum jadwal keberangkatan kapal, dan tempat untuk beristirahat sejenak bagi pengunjung setelah berpulang menuju pelabuhan. FREEDOM merupakan singkatan dari Fun \& Relax Express Entertainment for Domestic, setiap keyword mengandung makna tersendiri yang berhubungan dengan program yang terdapat didalam Freedom.

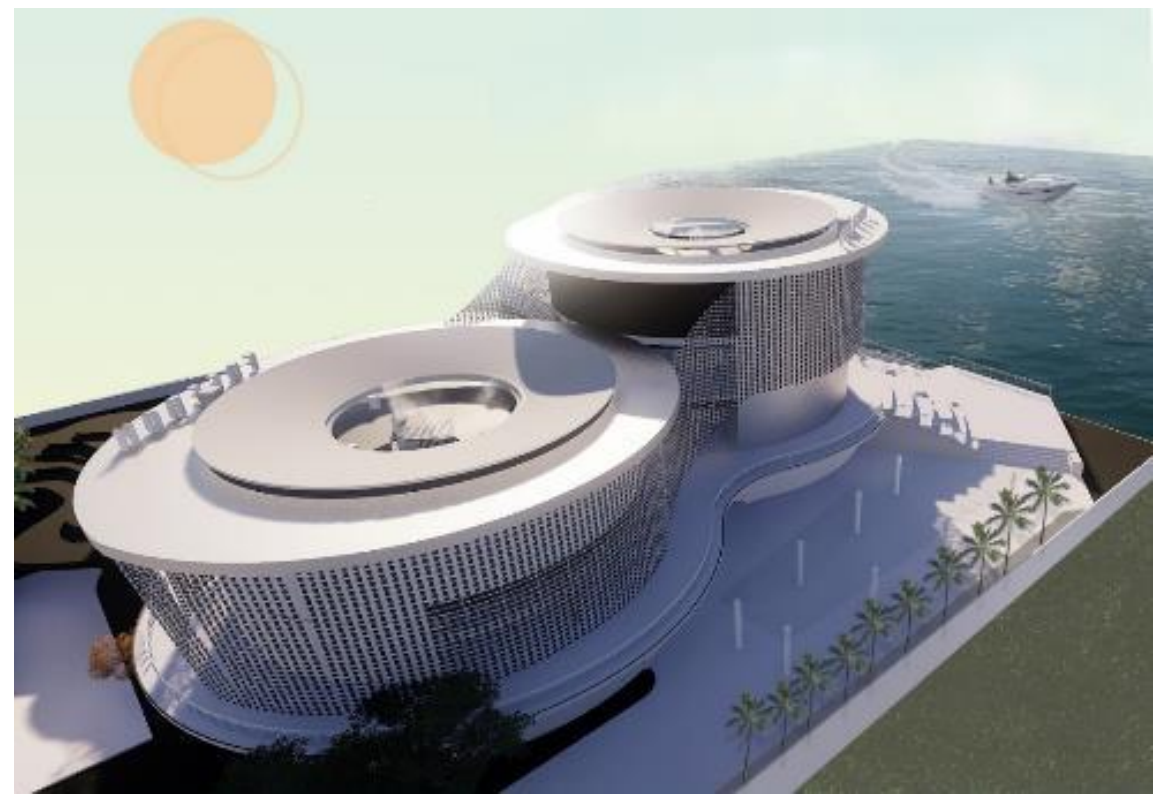

Gambar 8. Perspektif Eksterior FREEDOM Sumber : Penulis, 2019

Freedom terbagi menjadi 3 prgram utama, yaitu Entertainment, Commercial dan Relax Area. Pada area Entertainment terdapat Kids Area, Arcade Games, Mini Sport, Karaoke Box dan Seanema (cinema) yang berada dibangunan sayap utara (bangunan 4 lantai). Pada bangunan sayap selatan terdapat area Commercial, berupa F\&B dengan indoor dan outdoor area. Dan Relax Area yang terdapat dilantai 3 yang terdiri dari Transit Spod (SleepingPod). Sleep Area, Spa \& Reflexology dan Massage Cha.

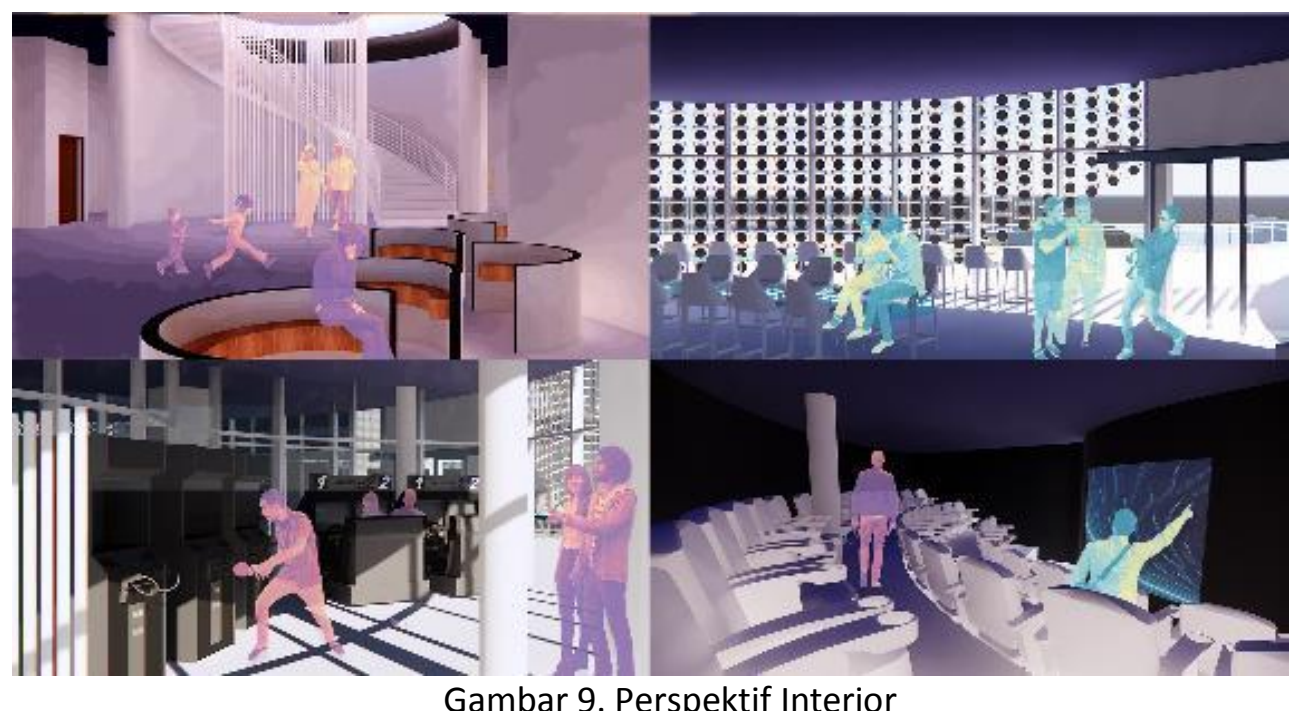

Sumber : Penulis, 2019 
Pada Area Outdoor terdapat Ampitheater yang berada dilantai dua menuju ke landscape, terdapat ConPark (Contour Park), Interactive Light Carpet, Pop Up Park \& Market, dan Live Music Area yang terdapat pada lantai kedua bangunan yang juga difungsikan sebagai connector antara bangunan sisi utara dan selatan.

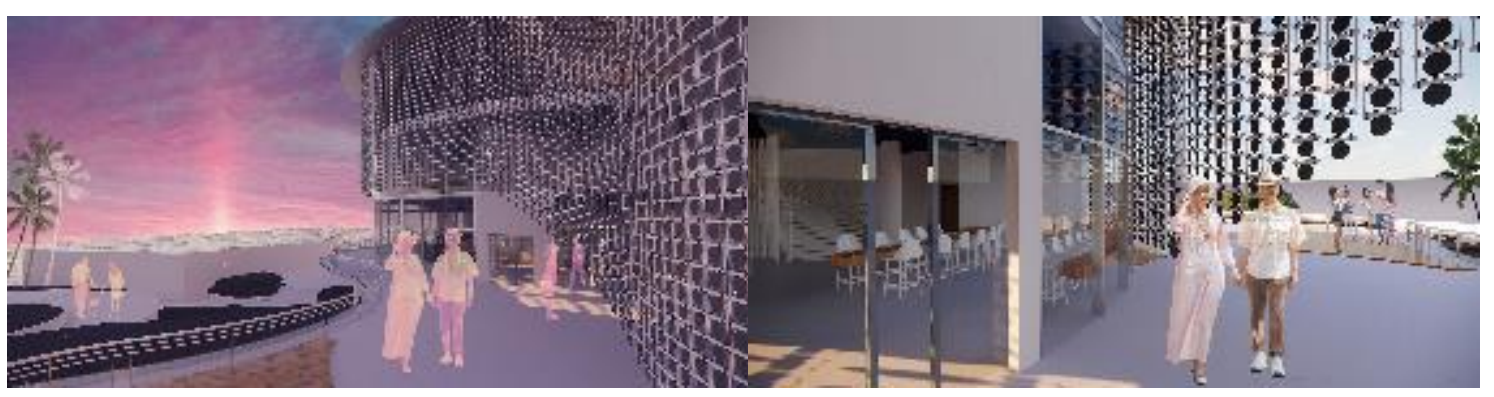

Gambar 10. Perspektif Eksterior Lantai 2

Sumber : Penulis, 2019

\section{KESIMPULAN DAN SARAN}

Penulisan ini bertujuan untuk mengusulkan program rest area bagi penumpang/pengunjung Pelabuhan Kaliadem, program berupa tempat bersenang-senang, bersantai dan peristirahatan sementara sembari pengunjung menunggu jadwal keberangkatan kapal. Dalam pendekatan desain telah dilakukan survei user dan lokasi Pelabuhan Kaliadem, dan mendapatkan program yang sesuai dengan kebutuhan user. Setelah melalui berbagai tahap dalam merancang proyek, dapat ditarik beberapa poin penting sebagai kesimpulan akhir;

a. Dalam melakukan perancangan arsitektur, diperlukan berbagai observasi, riset dan kajian literatur yang mendalam dan lengkap agar hasil perancangan terjawab dengan baik;

b. Sebelum meneliti dan merancang perlu diketahui fenomena dan isu yang terkait dengan tapak terpilih agar tidak terjerumus dengan desain yang tidak sesuai dengan konteks kawasan/tapak;

c. Sebagai arsitek, kita harus memiliki kemampuan untuk menelaah setiap proses menuju desain, memikirkan dengan matang setiap kata atau gambar yang kita hasilkan, jangan sampai keliru dan menghasilkan argumentasi yang salah.

d. Metode observasi user dalam menghasilkan desain merupakan salah satu metode yang penulis gunakan dalam proyek ini, dan metode ini menguatkan program utama desain, karena merupakan kebutuhan dari user itu sendiri.

\section{REFERENSI}

Badan Pusat Statistik. (2019). Jakarta. Kota Jakarta Utara Dalam Angka 2019. Jakarta: BPS

Badan Pusat Statistik. (2018). Jakarta. Kecamatan Penjaringan Dalam Angka 2018. Jakarta: BPS

Badan Pusat Statistik. (2015). Jakarta. Presentase Penduduk Miskin Menurut Kabupaten Kota Administrasi 2009-2013. Jakarta: BPS

Oldenburg, R. (1997). "The Great Good Place". Cambridge: De Capo Press Book

Sediawati, E. Sukada, Budi A. (2010). "Pentas Ilmu di Ranah Budaya : Sembilan Windu" hal. 99107 "Ruang". Denpasar: Pustaka Larasan

Umut, P. T. (2013). Urban Waterfront Regenerations, Advances in Landscape Architecture. Diakses pada 25/08/2019 dari :

Wiradi. (2018). Pengertian dan Definisi Metode Menurut Para Ahli. Diakses pada 25/08/2019 dari :

https://www.intechopen.com/books/advances-in-landscape-architecture/urban-waterfrontregenerationshttps://en.wikipedia.org/wiki/Fish farming

https://www.ruangguru.co.id/17-pengertian-dan-definisi-metode-menurut-para-ahli/ 
